Benha Veterinary Medical Journal
$\begin{gathered}\text { Official Jounal Issued by } \\ \text { Fetenty of } \\ \text { Eetrinary Medicine }\end{gathered}$
Original Paper

\title{
Clinical, hematological and biochemical assessment of dogs naturally infected with canine parvovirus before and after therapy
}

\author{
Heba El-Zahar ${ }^{1, *}$, Abdelkereem M. Morsi ${ }^{1}$ and Wafaa M. El-Neshwy ${ }^{2}$ \\ ${ }^{1}$ Internal Medicine, Department of Animal Medicine, Faculty of Veterinary Medicine, Zagazig University, Egypt. \\ ${ }^{2}$ Infectious Diseases, Department of Animal Medicine, Faculty of Veterinary Medicine, Zagazig University, Egypt.
}

\begin{tabular}{|c|c|}
\hline ARTICLE INFO & ABSTRACT \\
\hline $\begin{array}{l}\text { Keywords } \\
\text { Biochemical findings } \\
\text { Canine parvovirus } \\
\text { Clinical findings } \\
\text { Hematological findings } \\
\text { Rapid CPV test kit. } \\
\text { Received } 09 / 10 / 2019 \\
\text { Accepted } 29 / 12 / 2019 \\
\text { Available On-Line } \\
\text { 12/05/2020 }\end{array}$ & $\begin{array}{l}\text { To evaluate the effect of canine parvovirus infection on hematological and biochemical } \\
\text { parameters in dogs, forty-two dogs aged } 2-9 \text { months admitted to the Veterinary Hospital at } \\
\text { Faculty of Veterinary Medicine, Zagazig University and private clinics at Sharqia governorate } \\
\text { between August } 2018 \text { and August } 2019 \text { were included in the present study. The canine } \\
\text { parvovirus infected dogs }(\mathrm{n}=32 \text { ) were positive for the rapid CPV Ag test kit with clinical signs } \\
\text { of fever, diarrhea, vomiting, depression and anorexia. Hematological examination in canine } \\
\text { parvovirus infected dogs showed decreased hemoglobin, RBCs, PCV\% and leukocytes due to } \\
\text { lymphopenia and neutropenia compared to healthy control dogs ( } \mathrm{n}=10) \text {. The ALT, AST, } \\
\text { globulin, alkaline phosphatase and serum creatinine significantly increased. After treatment of } \\
\text { infected dog with intravenous fluid therapy, antibiotics, anti-emetics, hematological and } \\
\text { biochemical parameters were improved after recovery. We concluded that, canine parvovirus } \\
\text { infection has an effect on the hematological and biochemical findings dogs. }\end{array}$ \\
\hline
\end{tabular}

\section{INTRODUCTION}

Canine parvovirus infection is considered an important problem affecting dogs at an early stage of life and is an important cause of morbidity and mortality worldwide, it causes fever, diarrhea, vomiting and severe dehydration which predisposing to acute kidney injury (Nan et al., 2018). It is considered the main cause of diarrhea in dogs less than 6 months of age (Hackett and Lappin, 2003; Prittie, 2004; Yesilbag et al., 2007; Schulz et al., 2008). It usually affects dogs at any age, although puppies are more susceptible between 6 weeks and 6 months of age (Godsall et al., 2010; Iris et al., 2010). Adults with decreased or insufficient immunization program might be affected (Iris et al., 2010; Markovich et al., 2012). The pathogens spreads among dogs through fecal - oral route where the virus is shedded through feces 3 days after natural infection and continues for an incubation period of 3 - 4 weeks after the appearance of clinical disease (Decaro et al., 2005a; Godsall et al., 2010). Exposure of susceptible dogs to infected feces or vomits predispose to infection (Sykes, 2014). There are two types of canine parvovirus (CPV); CPV 1 and CPV 2. Most cases infected with CPV 1 are asymptomatic, while CPV 2 is mostly contagious (Nandi and Kumar, 2010a). Several studies were performed to describe the clinical features, hematological and biochemical parameters in dogs naturally (Azetaka et al., 1981; Carman and Povey, 1982) or experimentally (Hirasawa et al., 1987; Sutton et al., 2013; Parker et al., 2017) infected with canine parvovirus.
Canine parvovirus is most commonly manifested as gastroenteritis. The initial clinical signs are nonspecific and characterized by loss of appetite, depression, and lethargy (Lamm and Rezabek, 2008). Typical clinical signs include vomiting, mucoid to hemorrhagic diarrhea, depression and leucopenia especially neutropenia and lymphopenia (Duffy et al., 2010; Hackett, 2011). However not all dogs infected with canine parvovirus are presented with bloody diarrhea. Fever may be observed in most cases (Decaro et al., 2005b). The intestinal mucosa is disrupted results in atrophy in the intestinal villi and malabsorption with profuse diarrhea and vomiting, the diarrhea and vomiting in some cases are hemorrhagic (Turk et al., 1990).

In many small animal clinics, canine parvovirus is diagnosed based on the clinical signs and some can rely on the rapid CPV Test kits (Tinky et al., 2015). Although the most accurate method for diagnosis of canine parvovirus infection is the use of polymerase chain reaction on fecal samples which is highly recommended (Saasa et al., 2016). Canine parvovirus infection is usually accompanied by septicemia and toxemia which leads to systemic inflammatory response syndrome that progresses to multiple organ dysfunction and death (Turk et al., 1990). The dehydration status that follows parvovirus infection results in increased liver enzymes activity (van den Broek, 1990), which is predispose to the occurrence of acute kidney injury (Schmidt-Ott et al., 2007; Schoeman et al., 2013; van den Berg et al., 2018). Early kidney damage was observed in canine parvovirus infection accompanied by elevation of blood urea nitrogen and creatinine (van den Berg et al., 2018). Early detection of high-risk condition that put the kidneys and liver under acute

\footnotetext{
* Corresponding author: Dr. Heba El-Zahar, Internal Medicine, Department of Animal Medicine, Faculty of

Veterinary Medicine, Zagazig University, Egypt.
} 
stress allows introducing the suitable intensive treatment and might improve the outcome of canine parvovirus infection (van den Berg et al., 2018).

The aim of the present study was to investigate the effect of canine parvovirus infection on the hematological and biochemical parameters. Treatment trial was performed for diseased dogs to monitor the improvement in hematological and biochemical findings after therapy.

\section{MATERIAL AND METHODS}

\subsection{Animals and study design}

The present study was conducted on forty-two dogs aged between 2 and 9 months with different breeds (German shepherd, Golden, Griffon, Pit bull, Rottweiler and Husky) and average body weight of $8.8 \mathrm{~kg}$, admitted to Veterinary Hospital of Faculty of Veterinary Medicine, Zagazig University and to a private pets clinic in Sharkia governorate during the period between August 2018 and August 2019. The dogs were classified into two groups; control group (n $=10)$ and canine parvovirus group $(\mathrm{n}=32)$. Diseased dogs were diagnosed based on the clinical signs presented on admission and positive fecal CPV by rapid CPV Ag test kit. Following examination, the dogs were treated according to the standards for emergency care for pets. This study not includes experimental work, so the Institutional Animal Care and Use Committee, Zagazig University (ZU-IACUC) was not required. Owners of the dogs have approved to include their dogs in the current study.

\subsection{Clinical examination and samples collection}

The dogs under investigation were examined clinically and thoroughly investigated at the time of admission. Fecal swabs were collected from diseased dogs included in the present study and used directly for rapid CPV Ag test kit (Lot no. 2018061212, Zhenuri Biotech Co., Ltd., Shenzhen, China) according to the manufacturer's manual.

Blood samples were collected from all dogs, the sampling procedures were performed on admission $\left(\mathrm{T}_{0}\right)$ and 2 weeks following treatment $\left(\mathrm{T}_{1}\right)$ in diseased dogs, while in control dogs the sampling were performed once on admission $\left(\mathrm{T}_{0}\right)$. Blood was obtained from the cephalic vein and divided into two parts. First part was collected on EDTA tubes for whole blood samples and the $2^{\text {nd }}$ part in plain tubes for serum collection. EDTA samples were examined immediately for hematological findings, including RBCs, WBCs, and differential leucocytic count, PCV\%, hemoglobin and erythrocytic and anemia indices using CELL - DYN 3500 (Spectra Diagnostika, California, USA). Hepatic and renal functional parameters were analyzed using a blood chemistry analyzer (Konelab Prime 60i, Konelab, Finland) included serum creatinine, blood urea nitrogen; AST, ALT, Alkaline phosphatase, total protein, albumin and globulin.

\subsection{Therapeutic trials}

The diseased dogs were received symptomatic treatment after admission including intravenous fluid therapy, antibiotics (ampicillin $20 \mathrm{mg} / \mathrm{kg}$ in combination with metronidazole at a rate of $10 \mathrm{mg} / \mathrm{kg}$ through i/v route $3-4$ times daily), anti-emetics (Ondansetron $1 \mathrm{mg} / \mathrm{kg} \mathrm{i} / \mathrm{v}$ ) according to Martin et al. (2002), de Mari et al. (2003), Sykes (2014) and Mylonakis et al. (2016).

\subsection{Statistical analysis}

The results were statistically analyzed using SPSS 17.0 (SPSS Inc., Chicago, IL, USA) and were expressed as mean \pm standard deviation (SD). The differences between the diseased and control dogs were analyzed using $t$-test. After therapy $\left(T_{1}\right)$ results were compared to that obtained on admission $\left(\mathrm{T}_{0}\right)$ using $t$-test. The results were considered significant at a $\mathrm{p}<0.05$.

\section{RESULTS}

\subsection{Study population}

\subsection{Results of clinical examination}

According to the clinical examination and the results of rapid CPV Ag test kits, the dogs were classified into control dogs $(n=10)$ which were clinically healthy with no signs of the disease; there were no signs of diarrhea and negative fecal CPV Ag test. CPV infected dogs $(n=32)$ showed signs of fever, diarrhea which were hemorrhagic in 12 dogs $(37.5 \%)$ and without blood in $20 \operatorname{dogs}(62.5 \%)$, vomiting, depression and anorexia. The fecal CPV Ag test was positive. The case history revealed that the CPV diseased dogs were unvaccinated against parvovirus according to the owner's declaration. The dogs after treatment showed an improvement in the general health condition and disappearance of signs if diarrhea and dehydration.

\subsection{Hematological analyses}

Hematological examination table (1) showed that the hemoglobin concentration significantly decreased in canine parvovirus infected dogs compared to clinically healthy dogs. The erythrocytes were significantly decreased in canine parvovirus dogs compared to clinically healthy dogs. The packed cell volume in diseased dogs was significantly decreased compared to control dogs.

The leucocytes count, neutrophils and lymphocytes were significantly reduced in canine parvovirus infected dogs compared to clinically healthy dogs. The platelets, monocytes, eosinophils and basophils did not differ significantly.

\subsection{Biochemical analyses}

Biochemical examination table (2) showed that, serum albumin significantly decreased in canine parvovirus infected dogs compared to clinically healthy dogs. The serum globulin was significantly increased in diseased dogs compared to clinically healthy dogs. Serum ALT, AST, alkaline phosphatase and serum creatinine were significantly increased in canine parvovirus infected dogs compared to clinically healthy dogs. The serum total protein and blood urea nitrogen not differ significantly between the two groups.

\subsection{Treatment trials}

The diseased dogs were received an intensive care therapy included intravenous fluid therapy, antibiotic especially ampicillin at a dose rate of $20 \mathrm{mg} / \mathrm{kg}$, anti-emetics. The protocol for treatment was given for at least $3-4$ times daily until recovery. The hematological and biochemical analyses after therapy $\left(\mathrm{T}_{1}\right)$ were compared to that before therapy $\left(\mathrm{T}_{0}\right)$, the results are presented in table (1 and 2). Four dogs died during application of therapy due to severe dehydration and deterioration in general health condition. There was an improvement in the results of the hemoglobin, erythrocytes, 
packed cell volume, leucocytes, neutrophils and lymphocytes in blood samples after therapy compared to that before therapy. The serum albumin, globulin, serum ALT,
AST, alkaline phosphatase and creatinine values were significantly returned to normal values as in clinically healthy dogs.

Table 1 Hematological analysis of healthy control dogs and CPV infected dogs before ( $\left.\mathrm{T}_{0}\right)$ and 6 weeks after $\left(\mathrm{T}_{1}\right)$ treatment. Results are expressed as mean $\pm \mathrm{SD}$.

\begin{tabular}{lccc}
\hline Parameters & $\begin{array}{c}\text { Healthy } \\
\text { control dogs }\end{array}$ & $\begin{array}{c}\text { CPV infected dogs } \\
\text { before treatment }\left(\mathrm{T}_{0}\right)\end{array}$ & $\begin{array}{c}\text { CPV infected dogs } \\
\text { after treatment }\left(\mathrm{T}_{1}\right)\end{array}$ \\
\hline Hemoglobin $(\mathrm{g} / \mathrm{dl})$ & $14.4 \pm 0.45$ & $9.6 \pm 0.6^{*}$ & $13.7 \pm 0.02$ \\
RBCs cells $\times 10^{6} / \mu \mathrm{l}$ & $6.8 \pm 0.98$ & $4.2 \pm 0.63^{*}$ & $5.6 \pm 0.4$ \\
Packed cell volume $\%$ & $48 \pm 0.3$ & $34 \pm 0.1^{*}$ & $42 \pm 0.6$ \\
Platelets $\times 10^{3} / \mu \mathrm{l}$ & $300 \pm 1.2$ & $280 \pm 1.2$ & $310 \pm 0.8$ \\
WBCs $\times 10^{3} / \mu 1$ & $13.9 \pm 0.3$ & $5.61 \pm 0.4^{*}$ & $10.09 \pm 0.8$ \\
Neutrophils $\times 10^{3} / \mu \mathrm{l}$ & $9 \pm 0.02$ & $3.5 \pm 0.5^{*}$ & $7.8 \pm 0.9$ \\
Lymphocytes $\times 10^{3} / \mu \mathrm{l}$ & $3.68 \pm 0.05$ & $1.8 \pm 0.02^{*}$ & $2.98 \pm 0.01$ \\
Monocytes $\times 10^{3} / \mu \mathrm{l}$ & $0.9 \pm 0.01$ & $0.6 \pm 0.01$ & $1 \pm 0.01$ \\
Eosinophils $\times 10^{3} / \mu 1$ & $0.28 \pm 0.01$ & $0.2 \pm 0.01$ & $0.2 \pm 0.01$ \\
Basophils $\times 10^{3} / \mu 1$ & $0.12 \pm 0.01$ & $0.11 \pm 0.01$ & $0.12 \pm 0.01$ \\
\hline * Significant difference at $\mathrm{p}-\mathrm{value} \leq 0.05$. & &
\end{tabular}

Table 2 Biochemical analysis of healthy control dogs and CPV infected dogs before $\left(\mathrm{T}_{0}\right)$ and 6 weeks after $\left(\mathrm{T}_{1}\right)$ treatment. Results are expressed as mean $\pm \mathrm{SD}$.

\begin{tabular}{lccc}
\hline Parameters & $\begin{array}{c}\text { Healthy } \\
\text { control dogs }\end{array}$ & $\begin{array}{c}\text { CPV infected dogs } \\
\text { before treatment }\left(\mathrm{T}_{0}\right)\end{array}$ & $\begin{array}{c}\text { CPV infected dogs } \\
\text { after treatment }\left(\mathrm{T}_{1}\right)\end{array}$ \\
\hline Total Protein $(\mathrm{g} / \mathrm{dl})$ & $5.6 \pm 0.1$ & $5.8 \pm 0.24$ & $5.6 \pm 0.32$ \\
Serum Albumin $(\mathrm{g} / \mathrm{dl})$ & $3.9 \pm 0.32$ & $3.3 \pm 0.64^{*}$ & $3.8 \pm 0.02$ \\
Globulin $(\mathrm{g} / \mathrm{dl})$ & $1.6 \pm 0.01$ & $2.4 \pm 0.21^{*}$ & $1.8 \pm 0.04$ \\
Serum ALT (U/l) & $20 \pm 0.62$ & $53 \pm 0.89^{*}$ & $35 \pm 0.87$ \\
Serum AST (U/l) & $17 \pm 0.46$ & $45 \pm 0.74^{*}$ & $32 \pm 0.12$ \\
Alkaline phosphatase (U/l) & $84.2 \pm 0.95$ & $212 \pm 0.91^{*}$ & $156 \pm 2.65$ \\
Serum Creatinine (mg/d) & $0.9 \pm 0.01$ & $5.77 \pm 0.24^{*}$ & $1.2 \pm 0.05$ \\
Blood Urea Nitrogen (mg/dl) & $12.4 \pm 0.56$ & $13.6 \pm 0.85$ & $12.1 \pm 0.67$ \\
\hline * Significant difference at p-value $\leq 0.05$. & &
\end{tabular}

\section{DISCUSSION}

The canine parvovirus infection is the most common cause of enteritis in dogs and most commonly seen in dogs at the age of $2-9$ months. The morbidity and mortality rates were high especially in unvaccinated and/or untreated dogs (Prittie, 2004; Decaro et al., 2005a\&b). Clinical signs on admission were nonspecific including: depression, anorexia, fever and lethargy while the typical signs include: vomiting, diarrhea which is developed to hemorrhagic later on, these signs was attributed to gastrointestinal inflammation process; similar clinical findings were reported by Thomson and Gagnon (1980), Sharp et al. (2010) and Mylonakis et al. (2016). Inflammatory mediators especially Interleukin-1 are released at the site of the gastrointestinal inflammation (Goddard and Leisewitz, 2010). The diseased dogs were diagnosed canine parvovirus infection by the use of rapid CPV Ag test kit which is considered animal side test, accurate, easy and cheap test for detection of the canine parvovirus antigen in the fecal samples of diseased dogs, it is recommended as an easy tool for the confirmation of parvovirus infection in dogs (AL-Hosary, 2018; Awad et al., 2019).

Canine parvovirus infection impacts the hematological parameters where the RBCs, PCV\% and leucocytes count decreased significantly in canine parvovirus infected dogs compared to control dogs, which indicates signs of anemia manifested clinically by pale mucous membrane and general weakness. Leucopenia, neutropenia and lymphopenia was attributed to the cytotoxic effect of the virus on the hematopoietic cells and bone marrow during the acute phase of the disease, this was in agreement with a previous studies by Hankes et al. (1992) and Weiss et al. (1999). The Lowered PCV\% in canine parvovirus infected dogs was due to the intestinal hemorrhage and bleeding. The biochemical analyses showed significant increase in serum ALT, AST, Alkaline phosphatase and creatinine values in canine parvovirus infected dogs compared to clinically healthy. The changes in the albumin and globulin were significant which is usually observed in enteritis and resulted from malabsorption, decrease dietary intake and protein losses (Craven et al., 2011). Blood urea nitrogen did not differ significantly between groups and this was disagreed to a previous results by Bhat et al. (2013), who observed significant increase in blood urea nitrogen due to pre-renal uremia which might reflect a serious problem in the kidneys during the course of the disease, although a previous study by van den Berg et al. (2018) stated that the serum creatinine and serum urea nitrogen are insensitive markers for assessment of renal injury. ALT and AST was significantly increased in canine parvovirus infected dogs compared to control dogs, this might be resulted from the hepatic disorders and the development of inflammatory bowel disease (Berghoff and Steiner, 2011). The canine parvovirus infection is more likely to occur at an early stage of life; therefore, it is recommended for owners of puppies less than 16 weeks to avoid contact with dogs at high risk for canine parvovirus infection or during recovery stage (Markovich et al., 2012).

This protocol agreed to that provided by Sykes (2014), Martin et al. (2002) and de Mari et al. (2003). During the treatment of the diseased dogs, there were 4 dogs died due to general systemic impairment, which might be related to 
severe dehydration, anemia and kidney damage (Nandi and Kumar, 2010b).

\section{CONCULOSION}

The hematological and biochemical parameters were altered in dogs infected with canine parvovirus infection. Through clinical examination, rapid test kits are very important for diagnosis of canine parvovirus in dogs.

\section{CONFLICT OF INTEREST}

The authors declare that there is no conflict of interest

\section{ACKNOWLEDGEMENTS}

The authors would like to thank the staff members of Animal Medicine Department, Faculty of Veterinary Medicine, Zagazig University, Egypt for their support and guidance during this study.

\section{REFERENCES}

1. AL-Hosary, A., 2018. Detection and Molecular Characterization of Parvovirus Serotypes in Egypt. Journal of Advanced Veterinary Research, 8, $79-83$.

2. Awad, R., Attallah, A., Khalil, W., 2019. Prevalence of Canine Parvovirus Infection in Egypt: Reliability of Some Molecular Methods Used for its Diagnosis in Dogs. Journal of Biological Sciences, 19, 192 - 200

3. Azetaka, M., Hirasawa, T., Konishi, S., Ogata, M., 1981. Studies on canine parvovirus isolation, experimental infection and serologic survey. Nihon juigaku zasshi. The Japanese journal of veterinary science, 43, 243 - 255.

4. Berghoff, N., Steiner, J.M., 2011. Laboratory tests for the diagnosis and management of chronic canine and feline enteropathies. Vet Clin North Am Small Anim Pract41, 311328.

5. Bhat, A.A., Wadhwa, D.R., Singh, S.P., Singh, I., 2013. Haematological and biochemical analysis in canine enteritis. Vet World, 6, 380-383.

6. Carman, S., Povey, C., 1982. Successful experimental challenge of dogs with canine parvovirus-2. Canadian journal of comparative medicine : Revue canadienne de medecine comparee, 46, 33-38

7. Craven, M. Mansfield, C.S., Simpson, K.W., 2011 Granulomatous colitis of boxer dogs. Vet Clin North Am Small Anim Pract, 41, 433-445.

8. de Mari, K., Maynard, L., Eun, H.M., Lebreux, B., 2003. Treatment of canine parvoviral enteritis with interferonomega in a placebo-controlled field trial. Vet Rec, 152, 105108.

9. Decaro, N., Campolo, M., Desario, C., Elia, G., Martella, V. Lorusso, E., Buonavoglia, C., 2005a. Maternally-derived antibodies in pups and protection from canine parvovirus infection. Biologicals : journal of the International Association of Biological Standardization, 33, 261-267.

10. Decaro, N., Desario, C., Campolo, M., Elia, G., Martella, V., Ricci, D., Lorusso, E., Buonavoglia, C., 2005b. Clinical and virological findings in pups naturally infected by canine parvovirus type 2 Glu-426 mutant. J Vet Diagn Invest, 17, 133-138.

11. Duffy, A., Dow, S., Ogilvie, G., Rao, S., Hackett, T., 2010. Hematologic improvement in dogs with parvovirus infection treated with recombinant canine granulocyte-colony stimulating factor. J Vet Pharmacol Ther, 33, 352-356.

12. Goddard, A., Leisewitz, A.L., 2010. Canine parvovirus. Vet Clin North Am Small Anim Pract, 40, 1041-1053.
13. Godsall, S.A., Clegg, S.R., Stavisky, J.H., Radford, A.D., Pinchbeck, G., 2010. Epidemiology of canine parvovirus and coronavirus in dogs presented with severe diarrhoea to PDSA PetAid hospitals. Vet Rec, 167, 196-201.

14. Hackett, T., Lappin, M.R., 2003. Prevalence of enteric pathogens in dogs of north-central Colorado. Journal of the American Animal Hospital Association, 39, 52-56.

15. Hackett, T.B., 2011. Gastrointestinal complications of critica illness in small animals. Vet Clin North Am Small Anim Pract, $41,759-766$.

16. Hankes, G.H., Dillon, A.R., Ravis, W.R., 1992. Effects of lactated Ringer solution and prednisolone sodium succinate on dogs with induced hemorrhagic shock. American journal of veterinary research, 53, 26-33.

17. Hirasawa, T., Iwaki, S., Watanabe, K., Mikazuki, K., Makino, S., Hayashi, Y., 1987. Outbreak of canine parvovirus infection and its elimination in a closed beagle dog colony. Zentralblatt fur Veterinarmedizin. Reihe B. Journal of veterinary medicine. Series, B34, 598-606.

18. Iris, K., Leontides, L.S., Mylonakis, M.E., AdamamaMoraitou, K., Rallis, T., Koutinas, A.F., 2010. Factors affecting the occurrence, duration of hospitalization and final outcome in canine parvovirus infection. Res Vet Sci, 89, 174178.

19. Lamm, C.G., Rezabek, G.B., 2008. Parvovirus infection in domestic companion animals. Vet Clin North Am Small Anim Pract, 38, 837-850, viii-ix.

20. Markovich, J.E., Stucker, K.M., Carr, A.H., Harbison, C.E., Scarlett, J.M., Parrish, C.R., 2012. Effects of canine parvovirus strain variations on diagnostic test results and clinical management of enteritis in dogs. Journal of the American Veterinary Medical Association, 241, 66-72.

21. Martin, V., Najbar, W., Gueguen, S., Grousson, D., Eun, H.M., Lebreux, B., Aubert, A., 2002. Treatment of canine parvoviral enteritis with interferon-omega in a placebocontrolled challenge trial. Veterinary microbiology, 89, 115127.

22. Mylonakis, M.E., Kalli, I., Rallis, T.S., 2016. Canine parvoviral enteritis: an update on the clinical diagnosis, treatment, and prevention. Veterinary medicine, 7, 91-100.

23. Nan, L., Liu, Y., Ji, P., Feng, H., Chen, C., Wang, J., Liu, D., Cui, Y., Wang, Y., Li, Y., Zhou, E., Zhang, G., 2018. Trigger factor assisted self-assembly of canine parvovirus VP2 protein into virus-like particles in Escherichia coli with high immunogenicity. Virol J, 15, 103-109

24. Nandi, S., Kumar, M., 2010a. Canine parvovirus: current perspective. Indian J Virol, 21, 31-44.

25. Nandi, S., Kumar, M., 2010b. Canine parvovirus: curren perspective. Indian journal of virology : an official organ of Indian Virological Society, 21, 31-44.

26. Parker, J., Murphy, M., Hueffer, K., Chen, J., 2017 Investigation of a Canine Parvovirus Outbreak using Next Generation Sequencing. Scientific reports, 7, 9633-9638.

27. Prittie, J., 2004. Canine parvoviral enteritis: A review of diagnosis, management, and prevention. Journal of Veterinary Emergency and Critical Care, 14, 167-176.

28. Saasa, N., Nalubamba, K.S., kandawire, E., Siwila, J., 2016. Seroprevalence of Canine Parvovirus in Dogs in Lusaka District, Zambia. Journal of veterinary medicine, 2016, 4.

29. Schmidt-Ott, K.M., Mori, K., Li, J.Y., Kalandadze, A., Cohen, D.J., Devarajan, P., Barasch, J., 2007. Dual action of neutrophil gelatinase-associated lipocalin. Journal of the American Society of Nephrology, JASN18, 407-413.

30. Schoeman, J.P., Goddard, A., Leisewitz, A.L., 2013. Biomarkers in canine parvovirus enteritis. New Zealand Veterinary Journal, 161, 217-222.

31. Schulz, B.S., Strauch, C., Mueller, R.S., Eichhorn, W., Hartmann, K., 2008. Comparison of the prevalence of enteric viruses in healthy dogs and those with acute haemorrhagic diarrhoea by electron microscopy. The Journal of small animal practice, $49,84-88$ 
32. Sharp, C.R., DeClue, A.E., Haak, C.E., Honaker, A.R., Reinero, C.R., 2010. Evaluation of the anti-endotoxin effects of polymyxin B in a feline model of endotoxemia. Journal of feline medicine and surgery, 12, 278-285.

33. Sutton, D., Vinberg, C., Gustafsson, A., Pearce, J., Greenwood, N., 2013. Canine parvovirus type 2c identified from an outbreak of severe gastroenteritis in a litter in Sweden. Acta veterinaria Scandinavica, 55: 64-68

34. Sykes, J.E. 2014. Chapter 14 - Canine Parvovirus Infections and Other Viral Enteritides, In: Sykes, J.E. (Ed.) Canine and Feline Infectious Diseases. W.B. Saunders, Saint Louis, 141151.

35. Thomson, G.W., Gagnon, A., 1980. Canine parvoviral enteritis: a disease entity. The Canadian veterinary journal = La revue veterinaire canadienne, 21, 158

36. Tinky, S.S., Ambily, R., Nair, S.R., Mini, M., 2015. Utility of a rapid immunochromatographic strip test in detecting canine parvovirus infection compared with polymerase chain reaction. Vet World, 8, 523-526.
37. Turk, J., Miller, M., Brown, T., Fales, W., Fischer, J., Gosser, H., Nelson, S., Shaw, D., Solorzano, R., 1990. Coliform septicemia and pulmonary disease associated with canine parvoviral enteritis: 88 cases (1987-1988). Journal of the American Veterinary Medical Association, 196, 771-773.

38. van den Berg, M.F., Schoeman, J.P., Defauw, P., Whitehead, Z., Breemersch, A., Goethals, K., Daminet, S., Meyer, E., 2018. Assessment of acute kidney injury in canine parvovirus infection: Comparison of kidney injury biomarkers with routine renal functional parameters. Vet J, 242, 8-14.

39. van den Broek, A.H., 1990. Serum protein electrophoresis in canine parvovirus enteritis. Br Vet J, 146, 255-259.

40. Weiss, D.J., Evanson, O.A., Sykes, J., 1999. A retrospective study of canine pancytopenia. Vet. Clin. Pathol., 28, 83-88.

41. Yesilbag, K., Yilmaz, Z., Ozkul, A., Pratelli, A., 2007. Aetiological role of viruses in puppies with diarrhoea. Vet Rec, 161, 169-170. 